\title{
Klasifikasi Motif Citra Kain Sutera Bugis Mengunakan Metode Markerless Marker
}

\author{
Zulfahmiz Abd Gani \\ Program Studi Pascasarjana \\ STMIK Handayani Makassar \\ Makassar, Indonesia \\ Program Studi Sistem \\ Informasi STMIK Tidore \\ Mandiri Tidore, Indonesia \\ zulfahmiz.abd.gani@gmail,com
}

\author{
Syafruddin Syarif \\ Program Studi Teknik Elektro \\ Universitas Hasanuddin \\ Makassar, Indonesia \\ syafruddin.s@eng.unhas.ac.id
}

\author{
Yuyun \\ Program Studi Pascasarjana \\ STMIK Handayani Makassar \\ Makassar, Indonesia \\ yuyunwabula@handayani.ac.id
}

\begin{abstract}
Silk is one of the national cultural heritage with various motifs and patterns. This research aims to detect and classify the image of the silk cloth based on motive. This research uses Augemented Reality technology with Markerless Marker Tracking method. To display a 3D object, the proposed method uses a special pattern as a marker to recognize the fabric type. As a research sample, the authors used 10 types of bugis silk motifs. From the test results found that markers can detect fabric motifs in bright rooms and undetectable markers in dim rooms. The best distance in detecting markers is $10 \mathrm{~cm}-50 \mathrm{~cm}$. Meanwhile at a distance of $110 \mathrm{~cm}$, the marker cannot be detected.
\end{abstract}

Keywords: Markerless Marker Tracking, Silk Fabric Bugis, Marker, Augmented Reality

\section{Pendahuluan}

Menurut Undang Undang Republik Indonesia No 5 tahun 2017 Tentang Pemajuan Kebudayaan menyatakan bahwa keberagaman kebudayaan daerah merupakan kekayaan dan identitas bangsa yang sangat diperlukan untuk memajukan Kebudayaan Nasional Indonesia di tengah dinamika perkembangan dunia. Tuhan Yang Maha Esa telah menganugerahkan bangsa Indonesia kekayaan atas keberagaman suku bangsa, adat istiadat, bahasa, pengetahuan dan teknologi lokal, tradisi, kearifan lokal, dan seni. Keberagaman tersebut merupakan warisan budaya bangsa bernilai luhur yang membentuk identitas bangsa di tengah dinamika perkembangan dunia.[1]

Kain Sutera merupakan salah satu warisan budaya kebangaan bagi Indonesia khususnya di Provinsi Sulawesi Selatan. Kain sutera terdapat motif dan corak yang sangat banyak dan beraneka ragam sesuai dengan kultur masyarakat setempat yang beragam. Salah satu Kabupaten di Sulawesi Selatan terkenal dengan kain sutera adalah Kabupaten Wajo tepatnya di Kota Sengkang. Terdapat perbedaan motif dan corak khas dari masing-masing daerah dipengaruhi dengan letak geografis, kultur, dan sejarah daerah tersebut. Ragam motif yang terdapat dalam kain sutera seperti motif Bombang (ombak), artinya masyarakat bugis terkenal dengan budaya bahari (pelaut), motif Balo Renni (corak kecil) artinya hanya digunakan pada wanita dan pria yang menandakan mereka masih perawan dan perjaka, motif Balo Lobang pasangan dari Balo renni motif ini digunakan pria yang masih lajang, motif Tettong dan motif Makkalu serupa dengan motif Balo renni dan Ballo lobang perbedaanya dari kedua motif ini terletak pada jenis garis yang dipakai jika pada Ballo renni dan Ballo lobang kombinasi garis tegak dan melintang sedangkan motif Tettong berdiri tegak dan motif Makkalu melintang dan melingkar, dan motif Moppang merupakan motif yang susah ditemui motif ini tabu untuk dipakai diluar rumah oleh pria maupun perempuan. Motif ini hanya ditemui didalam kamar bagi mereka yang sudah berkeluarga, motif Ballo Cobo' 'yang digunakan pada acara lamaran karena motif ini melambangkan keteguhan hati dan keseriusan seorang lelaki untuk mendapatkan gadis pujaan hatinya motif Mappagiling motif tersebut dibuat oleh seorang wanita yang ditinggalkan oleh suaminya namun akhirnya suaminya kembali pulang karena melihat motif tersebut yang dibelinya dari seorang pedagang sutera yang menjual kain motif hasil tenunan istrinya. akat bugis, setiap warna memiliki makna tertentu seperti warna merah yaitu berani karena benar, putih yang berarti kesucian, hijau yang berarti subur, Motif Caca wali Yang memiliki makna filosofi bahwa barang siapa yang menanam kebaikan maka ia akan menuai kebaikan pula begitupun sebaliknya dan Motif Lagosi adalah tanda objeknya adalah selembar kain sutera dengan motif flora/bunga. Interpertan menunjukkan bahwa Lagosi merupakan nama suatu desa yang ada di Kecamatan Pammana, Kabupaten Wajo, Provinsi Sulawesi Selatan.[2] Salah satu permasalahannya setiap motif kain sutera bugis belum terindetifikasi secara digital.

Pengolahan citra digital (Digital Image Processing) adalah sebuah disiplin ilmu yang mempelajari tentang teknik-teknik mengolah citra. Citra yang dimaksud disini adalah gambar diam (foto) maupun gambar bergerak (yang berasal dari webcam). Sedangkan digital disini mempunyai maksud bahwa pengolahan citra/gambar dilakukan secara digital menggunakan computer[5]. Citra atau image adalah suatu cahaya pada bidang dua dimensi. Ditinjau dari sudut pandang matematis, citra merupakan fungsi kontinu dari intensitas cahaya pada bidang dua 
dimensi[6]. Menurut Ronald T. Azuma, defenisi dari Augmented Reality (AR) adalah menggabungkan dunia nyata dan virtual, bersifat interaktif secara real time dan merupakan animasi 3D [7]. Salah satu metode untuk mendeteksi citra pada Augmented Reality (AR) adalah markerless marker tracking. Metode ini tidak perlu menggunakan bingkai hitam dengan pola yang berada di bagian tengah bingkai. Markerless marker tracking banyak dikembangkan oleh perusahaan besar, mereka telah membuat aplikasi Augmented Reality (AR) dengan berbagai macam teknik markerless tracking sebagai teknologi andalan mereka, seperti face tracking, 3D object tracking, dan motion tracking[8]. Metode markerless marker tracking menggunakan Single marker sebagai penanda objek. Dalam augmented reality, penanda berfungsi untuk mendeteksi gambar yang dijadikan sebagai media marker dan hanya satu objek saja yang keluar, berbeda dengan multi marker yang dapat mendeteksi gambar yang dijadikan sebagai media marker dan banyak objek yang dapat keluar dalam satu waktu mendeteksi marker [9].

Tujuan dari penelitian ini adalah penerapan Augmented Reality (AR) untuk mengidentifikasi citra kain sutera bugis menggunakan metode markerless marker tracking. Pada penelitian sebelumnya, dilakukan oleh Satria [3] yang mengimplementasikan metode Markerless Marker dan metode FAST Corner Detection untuk mengetahui baik atau buruk implementasi aplikasi AR pengenalan budaya lokal Kalimantan Barat berbasis Android dan hasilnya kamera ponsel mendeteksi marker dengan sudut pandang diantara $0^{\circ}-75^{\circ}$ dan kadar cahaya sedang pada jarak 0 - $30 \mathrm{~cm}$. Sedangkan Alfi dkk.[4] mengeimplementasikan metode marker based tracking untuk mengetahui jarak pendeteksian marker minimum dan maximun dengan resolusi pixel pada aplikasi AR pembelajaran buah-buahan. Hasilnya jarak minimum adalah $10 \mathrm{~cm}$ dan jarak maximum adalah 86. Resolusi pixel minimum 32x50px gambar tidak terdeteksi oleh sistem sedangkan resolusi pixel 64x100px dan 96x150px dapat terdeteksi oleh sistem. Pada penelitian ini kami menerapkan pendekatan Markerless Marker Tracking untuk mengenali motif objek.

\section{KAJIAN TEORI}

Budaya menenun kain sutera di Sulawesi selatan berkembang pada tahun 1400 dengan corak garis dan horizontal. Kain sutera sendiri memiliki banyak warna, motif dan corak yang berbeda serta dibuat semenarik mungkin agar pemakainya merasa nyaman sendiri sehingga pada tahun 1600 berkembanglah corak kotak - kotak seiring dengan masa kejayaan islam di Sulawesi selatan [11]. Lippa bercorak kotak - kotak kemudian menjadi ciri khas corak lippa, baik sebagai corak maupun latar corak.

Sutera dalam bahasa lokal (Bugis) disebut "sabbe" merupakan hasil kerajinan tenun yang menjadi kebangaan suku Bugis, sehingga anggota masyarakat masih menggunakannya sebagai pakaian adat, terutama dalam upacara dan pesta tradisional [8].
Sutera memiliki motif dan warna khas, motif pada sutera pada umumnya menggunakan bentuk geometris, yaitu kotak - kotak.

Kain sutera yang menjadi warisan budaya, tetap menjadi kerajinan budaya yang dipakai pada acara adat maupun acara pesta. Hal tersebut sebagai indikasi bahwa kebudayaan tidak akan punah dan hilang. Permasalahan terletak pada peran serta masyarakat untuk menampilkannya secara nyata dengan medium gambar dan motif. Dokumentasi secar tertulis diperlukan, supaya mudah dipahami oleh semua pihak. Menuliskan suatu makna produk budaya termasuk cara menjaga budaya bangsa [10].

\section{METODE}

\section{A. Pengumpulan Data}

Teknik mengumpulkan data terkait untuk pengelompokkan motif kain sutera bugis yang didapatkan dari hasil pemotretan motif sebanyak 10 motif kain sutera bugis yaitu motif Ballo Cobo, Ballo Lobang, Ballo Renni, Ballo Tettong, Bombang, Caca Wali, Lagosi, Makkalu, Mappagiling dan Moppang.

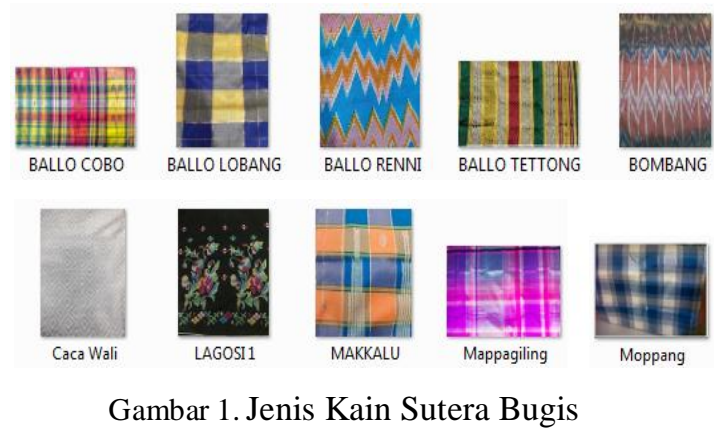

B. Metode Markerless Marker Tracking

Metode Markerless Marker Tracking atau sering disebut Markerless Augmented Reality yang merupakan teknik dalam menggunakan Vuforia dan QCAR (Qualcom Augmented Reality). Yaitu memungkinkan obyek yang berupa citra maya 3D ataupun 2D muncul pada layar perangkat android dan langsung ditempatkan diatas frame-frame Video yang ditangkap oleh kamera. Dengan metode ini pengguna tidak perlu lagi menggunakan sebuah marker untuk menampilkan elemen-elemen digital.

Cara kerja Metode Markerless marker yaitu dengan mendeteksi marker yang sesuai dengan inputan dalam databasenya, kemudian algoritma akan mengolah dan menampilkan informasi apa saja yang ada pada marker tersebut sesuai dengan apa yang telah dikerjakan sebelumnya, namun apabila markernya tidak sesuai dengan yang telah di inputkan dalam database maka informasi marker tidak akan di olah atau diproses. Sistem ini dirancang untuk mendeteksi citra kain sutera berdasarkan motif yang terdapat dalam database sehingga pada saat pendeteksian akan menampilkan objek 3D dan keterangan dari motif kain sesuai dengan marker yang telah dibuat sebelumnya. Apabila motifnya terdeteksi, maka langkah selanjutnya adalah menggunakan kamera smartphone pada jarak tertentu untuk mengetahui kinerja dari 
marker tersebut. Proses kerjanya ditampilkan pada Gambar 2 berikut :

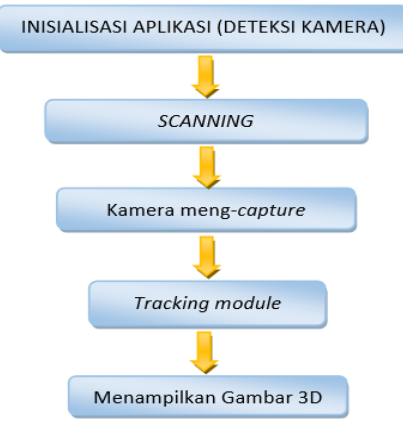

Gambar 2. Alur sistem metode Markerless Marker Tracking

1. Inisialisasi aplikasi: kamera mendeteksi citra yang telah ditentukan model 3D.

2. Scanning: membaca citra yang terdapat pada resource Vuforia dan QCAR

3. Meng-capture: menangkap citra yang telah ditentukan melalui kamera, yang kemudian diteruskan untuk dilakukan pengkonversian.

4. Tracking Module: melakukan pencocokan citra dalam data base. Karena menggunakan metode markerless, maka menggunakan trackable untuk memunculkan objek 3D.

5. Setelah tahap tracking maka objek akan tampil menjadi keluaran pada perangkat android.

\section{HASIL DAN PEMBAHASAN}

\section{A. Rancangan Sistem}

Gambar 3 menampilkan rancangan sistem menggunakan Augmented Reality (AR). Dimana user akan menginstal aplikasi, kemudian sistem akan mendeteksi marker dari motif kain. Apabila terdeteksi maka aplikasi akan merequest data dari database untuk dikirim dan ditampilkan pada aplikasi android. Kemudian pada gambar 4 menunjukkan user akan melakukan scaning terhadap motif kain. Kemudian dapat melihat objek 3D yang ditampilkan berupa motif dan keterangan motif kain. Pada saat user melakukan scanning pada motif kain, sistem akan mencocokkan objek yang terdapat dalam database jika data sesuai dengan marker, maka sistem menampilkan objek 3D dan keterangannya. Apabila data tidak sesuai dengan objek maka sistem tidak menampilkan objek. Kedua gambar dibawah ini menjelaskan juga bahwa ketika user membuka aplikasi maka akan tampil menu untuk melakukan start scanning objek kemudian akan dilakukan request data ke database server. Jika ditemukan datanya cocok, maka akan menampilkan data sesuai marker yang tersimpan didalam database namun apabila gambar tidak sesuai maka tidak akan menampilkan objek atau motif kain.

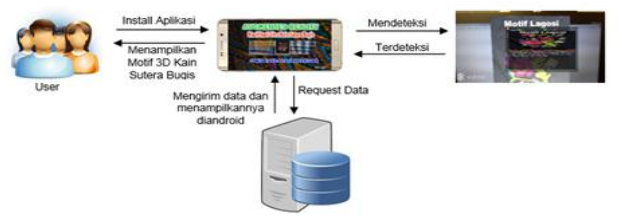

Gambar 3. Rancangan Sistem

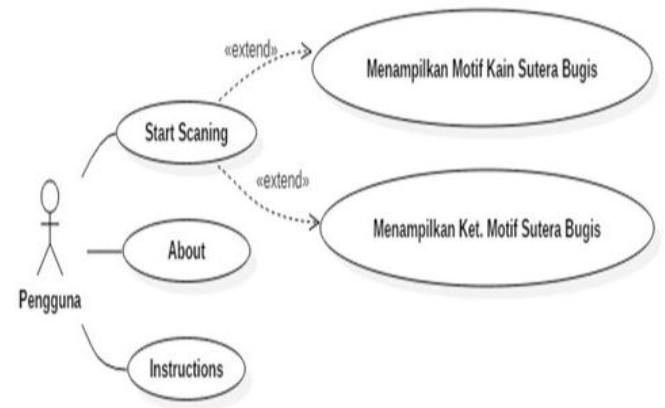

Gambar 4. Menu utama scan awal aplikasi

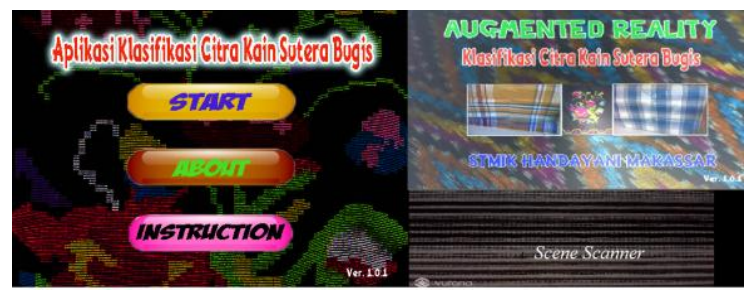

Gambar 5. Menu aplikasi

Pada gambar 5 menunjukkan tampilan awal yang merupakan scene dari aplikasi AR yaitu Aplikasi Klasifikasi Citra Kain Sutera Bugis yang menampilkan nama program. Menu ini sebagai halaman navigasi yang terdiri atas 3 tombol yaitu:

1. Tombol Start: Digunakan meng-scan objek pada kain sutera bugis. Setelah discan maka menampilkan objek 3D sesuai motif yang ada dalam database.

2. Tombol About: Menampilkan keterangan tentang aplikasi Augmented Reality Klasifikasi citra kain bugis berdasarkan motif.

3. Tombol Instruction: Menampilkan panduan penggunaan aplikasi Augmented Reality Klasifikasi citra kain bugis.

Selain itu Pada gambar 5 menunjukkan juga Scene Scanner. Tombol ini digunakan untuk masuk kedalam proses pengambilan gambar atau scanning dengan menggunakan kamera yang diarahkan ke marker atau objek motif kain. Pada saat kamera diarahkan ke marker atau objek 3D, kain sutera maka akan muncul.

\section{B. Pengujian Sistem}

1. Pengujin Fungsional System

Dalam penelitian ini, kami melakukan pengujian pada 10 (Sepuluh) motif kain sutera dengan menampilkan objek 3D. Tampilan screen shoot hasil pengujian untuk menampilkan 10 motif yang sesuai dengan marker yang telah ditentukan: 
Klasifikasi Motif Citra Kain Sutera Bugis Mengunakan Metode Markerless Marker

Tabel 1. Hasil pengujian pada sistem yang dibangun

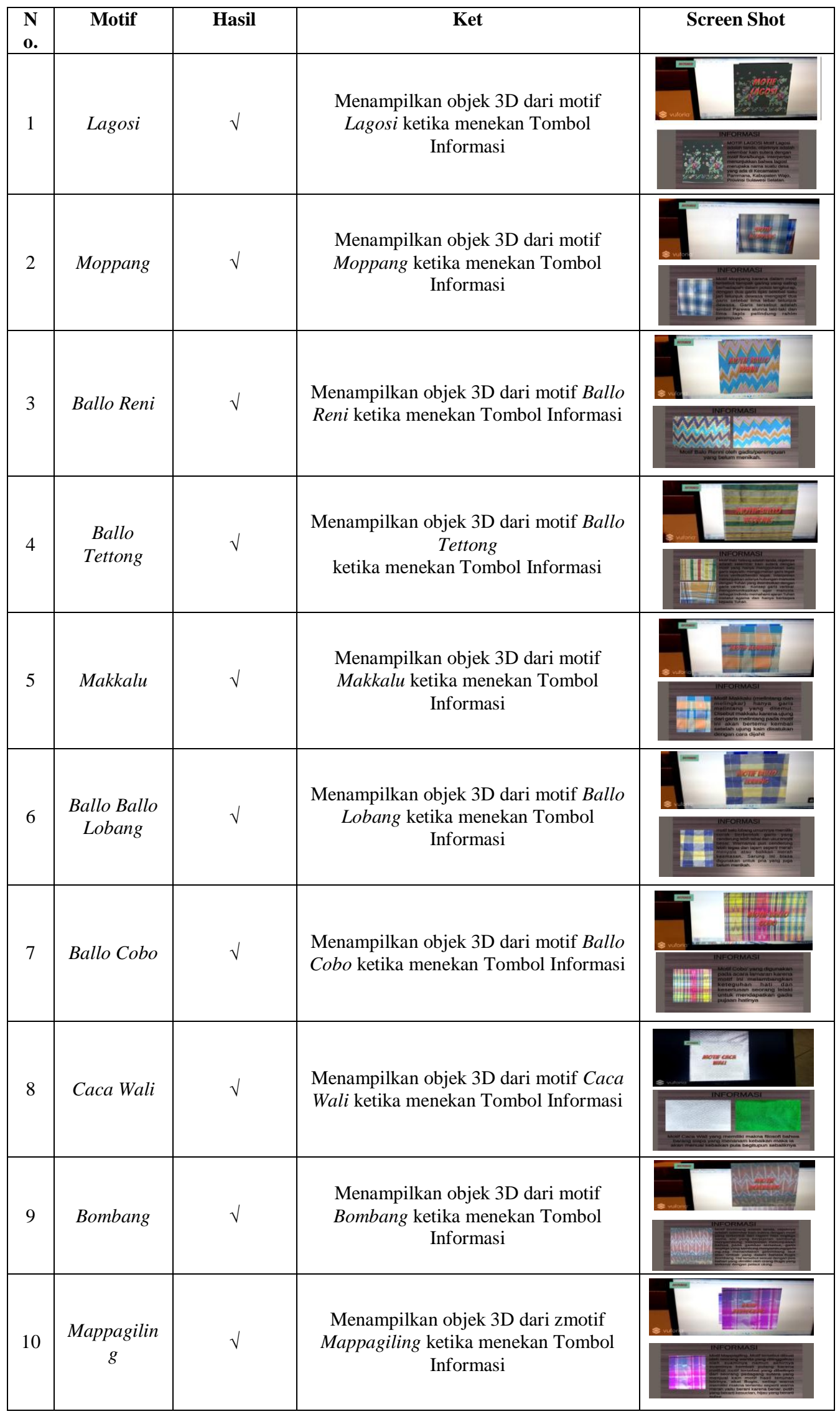


2. Pengujian Intensitas

Pengujian ini menggunakan 3 parameter yaitu kurang, sedang, dan terang (eerah), proses pengujian citra secara intesitas adalah melakukan proses terhadap intesitas cahaya pada kondisi di dalam dan luar ruangan, sehingga dapat diketahui hasil dari marker tersebut. Defenisi terang pada pengujian ini adalah pencahayaan yang baik dengan menggunakan cahaya lampu (sedang) saat berada dalam ruangan serta diluar ruangan menggunakan cahaya matahari (terang) sehingga hasil yang diperoleh marker terdeteksi dengan cepat, sedangkan redup (kurang) adalah kurangnya pencahayaan sehingga marker tidak terdeteksi. Tabel 2 menampilkan hasil penggujian keseluruhan motif batik yang telah di ujicoba. Secara umum semua sampel kain yang di uji, jika dalam ke cahaya kurang maka marker tidak dapat menedeteksi. Sebaiknya, dalam kondisi cahaya sedang maupun cahaya terang maka marker gambar dapat mengenali objek atau dapat terdeteksi.

Tabel 2. Hasil pengujian Intensitas keadaan cahaya

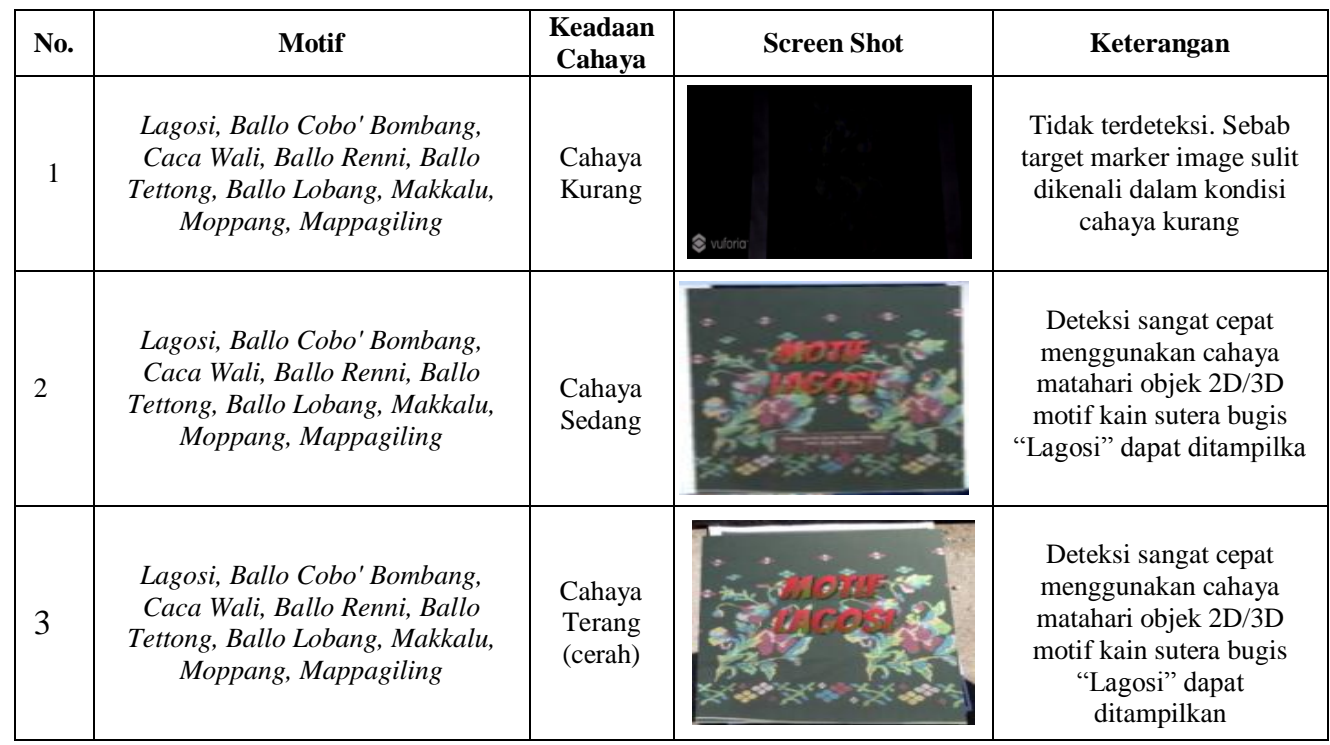

\section{Pengujian Marker}

Pengujian ini menggunakan jarak dan waktu. Pengujian ini untuk mengetahui tingkat keakuratan marker ketika kamera mendeteksi objek pada jarak dan waktu tertentu. Sehingga dapat mengetahui hasil dari masing - masing objek yang terdeteksi oleh kamera. Keberhasilan dari pengujian menggunakan symbol $(\sqrt{ }$, berhasil) dan simbol (-, gagal). Pada pengujian marker, dilakukan foto objek dengan dua kali pengujian yaitu hasil 1 dan hasil 2 (table 3 ). Jarak pengambilan objek dari 1- $90 \mathrm{~cm}$ semuanya berhasil dan pada saat pengukuran dengan jarak $110 \mathrm{~cm}$, camera tidak dapat melakukan penangkapan gambar. Ini berarti bahwa jarak $110 \mathrm{~cm}$ dan diatasnya, maka marker tdak dapat terdeteksi
Tabel 3. Hasil pengujian Marker menggunakan jarak dan waktu

\begin{tabular}{|c|c|c|c|c|c|}
\hline Motif & $\begin{array}{c}\text { Jarak } \\
\text { (cm) }\end{array}$ & Jam & Kondisi & $\begin{array}{c}\text { Hasil } \\
1\end{array}$ & $\begin{array}{c}\text { Hasil } \\
2\end{array}$ \\
\hline \multirow{15}{*}{$\begin{array}{c}\text { Lagosi, } \\
\text { Ballo Cobo' } \\
\text { Bombang, } \\
\text { Caca Wali, } \\
\text { Ballo Renni, } \\
\text { Ballo } \\
\text { Tettong, } \\
\text { Ballo } \\
\text { Lobang, } \\
\text { Makkalu, } \\
\text { Moppang, } \\
\text { Mappagiling }\end{array}$} & \multirow{3}{*}{10} & 07.12 & Pagi & $\sqrt{ }$ & $\sqrt{ }$ \\
\hline & & 12.20 & Siang & $\sqrt{ }$ & $\sqrt{ }$ \\
\hline & & 16.14 & Sore & $\sqrt{ }$ & $\sqrt{ }$ \\
\hline & \multirow{3}{*}{30} & 08.16 & Pagi & $\sqrt{ }$ & $\sqrt{ }$ \\
\hline & & 10.30 & Siang & $\sqrt{ }$ & $\sqrt{ }$ \\
\hline & & 17.15 & Sore & $\sqrt{ }$ & $\sqrt{ }$ \\
\hline & \multirow{3}{*}{50} & 08.12 & Pagi & $\sqrt{ }$ & $\sqrt{ }$ \\
\hline & & 13.20 & Siang & $\sqrt{ }$ & $\sqrt{ }$ \\
\hline & & 16.14 & Sore & $\sqrt{ }$ & $\sqrt{ }$ \\
\hline & \multirow{3}{*}{90} & 08.10 & Pagi & $\sqrt{ }$ & $\sqrt{ }$ \\
\hline & & 12.20 & Siang & $\sqrt{ }$ & $\sqrt{ }$ \\
\hline & & 16.14 & Sore & $\sqrt{ }$ & $\sqrt{ }$ \\
\hline & \multirow{3}{*}{110} & 08.19 & Pagi & - & - \\
\hline & & 10.39 & Siang & - & - \\
\hline & & 17.18 & Sore & - & - \\
\hline
\end{tabular}




\section{KESIMPULAN DAN SARAN}

Berdasarkan hasil penelitian maka didapat kesimpulan yaitu aplikasi AR ini digunakan untuk mendeteksi motif dan mengklasifikasikan berdasarkan keterangan motif bukan menentukkan jenis kain sutera bugis. ketika aplikasi AR ini terinstal maka database terinclude dan pada saat pendeteksian aplikasi AR ini hanya mendeteksi marker yang sesuai dengan marker dalam database. Dari hasil pengujian 10 motif kain sutera bugis semua motif berhasil terdeteksi dengan menampilkan objek 2D/3D dan keterangannya. Kemudian hasil penggujian menggunakan intensitas cahaya, ditemukan bahwa dalam keadaan cahaya kurang, marker tdak terdeteksi. Dan terakhir pengujian marker adalah jarak objek sama dengan atau lebig dari $110 \mathrm{~cm}$ maka objek kain tdak terdeteksi. Aplikasi AR ini menggunakan metode markerless marker tracking dengan menampilkan hasil pendeteksian sesuai dengan marker tracking yang telah dibuat. Marker yang digunakan adalah single marker, satu penanda dalam mendeteksi gambar yang dijadikan sebagai media marker dan hanya satu objek saja yang keluar. Aplikasi ini menggunakan database internal dan belum bisa menyimpan hasil pendeteksian marker atau objek sehinggadiharapkan kepada peneliti selanjutnya dapat menambahkannya. Aplikasi AR ini tidak dapat mendeteksi jenis kain sehingga diharapkan kepada peneliti selanjutnya dapat menambahkannya berdasarkan jenis dan kualitas kain. Data motif yang digunakan adalah 10 (sepuluh) motif kain sutera bugis diharapkan kepada peneliti selanjutnya dapat menambahkanya agar lebih kompleks.

\section{DAFTAR PUSTAKA}

[1] U. Dasar, "Undang-Undang Republik Indonesia Nomor 5 Tahun 2018," 1945.

[2] H. Cangara, T. Bahfiarti, S. Informasi, and U. Hasanuddin, "Makna Pesan Komunikasi Motif Kain Sutera," Komun. Kareba, vol. 4, no. 1, pp. 37-45, 2015.

[3] S. I. W. Putra, "Implementasi Teknologi Markerless Augmented Reality Menggunakan Metode Algoritma Fast Corner Detection Berbasis Android ( Studi Kasus Multimedia Buku Interaktif Kebudayaan Lokal Kalimantan Barat )," Coding J. Komput. dan Apl., vol. 07, no. 01, pp. 1-10, 2019.

[4] A. Syahrin, M. E. Apriyani, and S. Prasetyaningsih, "Analisis Dan Implementasi Metode Marker Based Tracking Pada Augmented Reality Pembelajaran BuahBuahan," Komputa J. Ilm. Komput. dan Inform., vol. 5, no. 1, pp. 11-17, 2016, doi: 10.34010/komputa.v5i1.2433.

[5] P. N. Lhokseumawe, K. Pengantar, rahayu deny danar dan alvi furwanti Alwie, A. B. Prasetio, and R. Andespa, "Tugas Akhir Tugas Akhir," J. Ekon. Vol. 18, Nomor 1 Maret201, vol. 2, no. 1, pp. 41-49, 2010.
[6] I. F. Noor, H. Tolle, and W. S. Wardhono, "Rancang Bangun Aplikasi Augmented Reality Pemilihan Sepatu Berdasarkan Ukuran Kaki Pengguna," J. Pengemb. Teknol. Inf. dan Ilmu Komput. Univ. Brawijaya, vol. 2, no. 4, pp. 1675-1682, 2018.

[7] J. Wither, Y. T. Tsai, and R. Azuma, "Indirect augmented reality," Comput. Graph., vol. 35, no. 4, pp. 810-822, 2011, doi: 10.1016/j.cag.2011.04.010.

[8] M. Qori'Untiarasani, H. Haryanto, and E. Astuti, "Pembangunan Perangkat Lunak Interaktif Berbasis Markerless Augmented Reality Untuk Pengenalan Hewan Pada Taman Kanak," Techno. Com, vol. 14, no. 2, pp. 159-164, 2015.

[9] M. E. Apriyani and R. Gustianto, "Augmented Reality sebagai Alat Pengenalan Hewan Purbakala dengan Animasi 3D menggunakan Metode Single Marker," J. INFOTEL - Inform. Telekomun. Elektron., vol. 7, no. 1, p. 47, 2015, doi: 10.20895/infotel.v7i1.29.
Copyright @2016 PROtek : Jurnal Ilmiah Teknik Elektro c) (i) (2) lisensi Creative Commons Attribution 4.0 EY NC SA International Licens 